\title{
Correlation between the cocaine- and amphetamine-regulated transcript in the pyloric section of the abomasum and fat deposition in bulls' carcasses
}

\author{
Krzysztof Młynek ${ }^{1}$, Izabela Janiuk², Adam Oler ${ }^{3}$, Marcin Maj $^{1}$, Lidia Borkowska ${ }^{4}$
}

${ }^{1}$ Siedlce University of Natural Science and Humanistes, Department of Cattle Breeding and Milk Evaluation, ${ }^{2}$ Department of Vertebrate Morphology, Siedlce, Poland

${ }^{3}$ University of Technology and Life Sciences, Department of Cattle Breeding, Bydgoszcz, Poland ${ }^{4}$ Siedlce University of Natural Science and Humanistes, Department of Biology, Siedlce, Poland

Received July 21, 2014

Accepted June 24, 2015

\begin{abstract}
The study was aimed at investigating the relationship between the number of cocaine- and amphetamine-regulated transcript (CART) structures present in the pyloric section of the abomasum and fat accumulation in carcasses of bulls - crosses of Polish Lowland Black-andWhite cows mated with Limousin bulls. The bulls were slaughtered at the mean age of 629 days and body weight of $597 \mathrm{~kg}$. The distribution of cocaine- and amphetamine-regulated transcriptimmunoreactive in the pyloric section of abomasum was assessed on the basis of CART positive immunohistochemical reactions. Significant interdependence was found between the number of CART structures and carcass adiposity and the fat content of the longissimus lumborum muscle. The identified tendency for fat tissue increase in the carcasses was accompanied by a lower concentration of the structures. In the endocrine system cell the greatest number of immunopositive cells were found; ranging from 28.9 in animals more obese to 37.8 with the smallest amount of fat accumulated. The lowest numbers of immunopositive cells, ranging from 2.4 to 3.9 were noted in the submucous plexus layer. Slightly more structures were observed in nerve fibres and the myenteric plexus, at 2.9 and 4.7 , respectively. The number of CART in the endocrine system was correlated with subcutaneous fat $(-0.451)$ and marbling $(-0.514)$. The amount of CART in these anatomical layers was significantly correlated with the thickness of subcutaneous fat $(-0.541$ and -0.636$)$ and the weight of perinephric fat $(-0.487$ and -0.672$)$. The results confirm that CART is an important neurotransmitter that participates in the regulation of fat deposition in the body. It must be stressed that the correlations with the analysed fat deposition indices concerned the adiposity indicators influencing the commercial value of carcasses and the meat traits important to the consumer.
\end{abstract}

Cattle, fatness score, adiposity, CART, neuropeptides

The commercial value of bull carcasses and the meat indicators to which consumers pay attention at purchase are developed during cattle fattening. The synergy in the effect of environmental and physiological factors is primarily associated with the feeling of satiety and the orexic reflex (Okumura et al. 2000; Vettor et al. 2002; Hunter et al. 2004; Valassi et al. 2008). The food intake and energetic balance are, however, indirectly regulated by numerous orexigenic and anorexigenic neurotransmitters generated in the hypothalamic area (Koylu et al. 1997; Kong et al. 2003; Vrang et al. 2006). By affecting numerous digestive tract functions, neuroendocrine mechanisms responsible for peptide secretion participate, e.g., in the digestion, lipid metabolism, energetic balance and hormonal equilibrium maintenance (Rohner-Jeanrenaud et al. 2002; Baranowska et al. 2004; Smith et al. 2010).

One of the least known neuropeptides, involved in food intake and lipid metabolism is the cocaine- and amphetamine-regulated transcript (CART) identified by Douglass et al. (1995). Released in subthalamic nuclei, it signals the feeling of satiety. Its action in the metabolic lipid pathway is conducive to lower fat accumulation (Rohner-

Address for correspondence:

Krzysztof Młynek

Department of Cattle Breeding and Milk Evaluation

Siedlce University of Natural Science and Humanistes

Siedlce, Poland 
Jeanrenaud et al. 2002; Kong et al. 2003; Schwartz et al. 2003; Lucidi et al. 2005). Cocaine- and amphetamine-regulated transcript also influences growth intensity (Ajaet al 2001; Wortleyet al 2004; Młynek and Janiuk 2013) and can lead to body weight decrease (Larsen et al. 2000; Yang et al. 2005). It has been proved that CART presence in the GI tract is associated with gastric acid secretion, peristalsis, and stomach and colon emptying (Koylu et al. 1997; Wierup et. al. 2007). However, Thim et al. (1999) suggest that its peripheral activity may be different from the central activity.

The vast majority of studies analysing CART have been conducted with the use of laboratory animals (Wierup et al. 2004; Méndez-Díaz et al. 2009), namely pigs, and sheep (Wierup et al. 2007; Arciszewski et al. 2008). Some of them refer to humans (Kasacka and Piotrowska 2012; Banke et al. 2013). There are few sources available dealing with the CART activity in cattle, and the majority of articles mostly discuss CART location in the stomach and the nervous system (Kobayashi et al. 2006; Zhang et al. 2008; Arciszewski et al. 2009; Smithet al. 2010; Janiuk et al. 2013). Until now, no studies have been performed to analyse the relationship between CART and functional traits of the organism.

As the commercial value of raw meat depends, among others, on the amount of fat accumulated in the carcass and meat, exploration of mechanisms involved in feed intake and digestion control in cattle is indispensable to improve production efficiency and to obtain high-quality beef carcasses and meat.

Considering the above argument, studies were conducted to determine correlations between CART-IR concentration in the wall of the pyloric section of the abomasum and indices showing the amount of fat accumulated in the bodies of bulls.

\section{Materials and Methods}

A total of 20 bulls that were crosses of Polish Lowland Black-and-White cows mated with Limousin bulls, were used in the study. The animals originated from three farms with similar feeding and housing conditions. In the autumn-winter period all the heifers were fed hay (ad libitum), corn silage (approximately $10 \mathrm{~kg} / \mathrm{day}$ ) and compound cereal meal, and in the summer they received green fodder (ad libitum), crushed cereal grain, and a small addition of hay. The fattening period of calves started approximately at their age of $6^{\text {th }}$ months. The diets were formulated according to IZ-INRA (2001) feeding standards (with the use of INRAtion software, version 2.x.x.) drawing on the earlier chemical analysis of feeds and calculating their nutritive value. The animals were fed with rations that provided their maintenance requirement. The total requirements for nutrients were determined based on the IZ-INRA system.

The bulls were slaughtered between the ages of 527 to 784 days (mean $629 \pm 81$ ). The body weight of the slaughtered animals ranged from 451 to $742 \mathrm{~kg}$ (mean $597 \pm 83$ ). After post-slaughter carcass processing the classification according to the EUROP system was performed on hot carcasses. The classification included the determination of fat cover expressed as I-very low, II-low, III-average, IV-high or V-very high fat.

Segments of the longissimus lumborum (LL) muscle were collected an hour post slaughter. The marbling denoting the intensity of fat growth within the muscle was assessed using the point method ( 1 - lack of growth; 5 - very intensive growth). The fat content was determined by the Soxhlet method. External fat was measured at a height of vertebra lumbales V (roast beef). Perinephric fat carcasses were harvested during dissection. The analyses were performed $48 \mathrm{~h}$ after slaughter (the meat was stored in plastic bags at $4{ }^{\circ} \mathrm{C}$ ).

\section{Microscopy analysis}

The samples were analysed with an Olympus BX41 light microscope with a video channel connected to a PC equipped with a Cell-B image analysis program (Olympus 114 Corp., Tokyo, Japan). While recording the images, particular attention was paid to the distribution of the structures showing immunoreactivity (CART-IR) to the analysed antigen. Morphometric analysis was applied to diffuse endocrine system cells that produced dark brown stains.

The mean numbers of CART-IR were counted in 10 randomly selected fields of vision $\left(0.785 \mathrm{~mm}^{2}\right)$, at a $200 \times$ zoom $(20 \times$ lens and $10 \times$ eyepiece). The mean numbers of these cells containing CART-IR were counted in the structures of the pyloric section of the abomasum: neuroendocrine cells, the submucous plexus, nerve fibres and the myenteric plexus. 
Immunohistochemistry

The experimental material was sampled during a routine carcass dissection procedure applied at meat plants. The stomachs of the analysed bulls were prepared within 30 min post mortem. The fragments of the abomasum were sampled and the tissue was ex tempore fixed in $4 \%$ buffered formalin for $72 \mathrm{~h}$ at room temperature. Subsequently, paraffin blocks were made using standard procedures. The paraffin blocks were cut to $4 \mu \mathrm{m}$ sections and mounted on to SuperFrost ${ }^{\circledR}$ Plus slides (Menzel, Braunschweig, Germany) and dried overnight at $37^{\circ} \mathrm{C}$, followed by $1 \mathrm{~h}$ at $60{ }^{\circ} \mathrm{C}$. Paraffin embedded sections were deparaffinized and hydrated through graded alcohols (pure ethanol) to water.

For antigen retrieval, the sections were pre-treated in a pressure chamber and heated for $1 \mathrm{~min}$ at 21 psi (one pound force per square inch $(1 \mathrm{psi})=6.895 \mathrm{kPa})$ at $121{ }^{\circ} \mathrm{C}$, using target retrieval solution at $\mathrm{pH} 9.0$ (S 2367 ; Dako Denmark A/S, Glostrup, Denmark). After cooling to room temperature, the sections were incubated with peroxidase blocking reagent (S 2001; Dako Denmark A/S, Glostrup, Denmark) for 10 min to block endogenous peroxidase activity.

The sections with the primary antibody for CART, rabbit polyclonal CART antiserum H-003-61 (Phoenix Pharmaceuticals, Inc. Mountain View, CA, USA) were incubated overnight at $4{ }^{\circ} \mathrm{C}$ in a humidified chamber. The antiserum was diluted 1: 10.000 in antibody diluent (S 0809; Dako Denmark A/S, Glostrup, Denmark). The EnVision method was used for CART immunohistochemistry according to Herman and Elfont (1991). This procedure was followed by incubation with secondary rabbit antibody conjugated to horseradish peroxidaselabelled polymer (K4011; Dako Denmark A/S, Glostrup, Denmark). The bound antibodies were visualized by incubation with liquid 3, 3'-diaminobenzidine substrate chromogen for $1 \mathrm{~min}$. Finally, the sections were counterstained with haematoxylin QS (H 3404; Vector Laboratories, Burlingame, CA), mounted and evaluated by light microscopy. Sections were washed with wash buffer (S 3006; Dako Denmark A/S, Glostrup, Denmark) between each step.

Specificity tests for the CART antibody included a negative control, where the antibodies were replaced by normal rabbit serum (Vector Laboratories) at the same dilution and a positive control was prepared with a different tissue recommended by the manufacturer; we used rat hypothalamus.

\section{Statistical analysis}

Statistical procedure ANOVA involved the calculation of the following traits for the analysed carcass fatness score class (I-IV). Unpaired Student's $t$-test was used to compare and to evaluate the significance of the differences in means between the analysed groups, tested by Tukey's LSD $(P \leq 0.05)$. Data are presented as the least square means (LSM), the standard error of the mean (SE), the level of significance of the effects and interactions. Relationships between the evaluated variables were calculated by Pearson's correlation coefficient. Significance of the correlation were considered at the level of $P \leq 0.05$. All statistical procedures were done using the programme Statistica version 10.0 (StatSoft Inc., Tulsa, USA).

\section{Results}

The data in Table 1 show that carcasses classified as fat, with higher values of fat deposition indicators, generally had fewer immunoreactive structures (CART-IR) in the layers of the pyloric part of abomasum. The observed tendency concerned indices connected with the fat cover of the carcasses: external fat $(P \leq 0.05)$ and perinephric fat weight $(P \leq 0.05)$, and

Table 1. Fat deposition indicators and the number cells of CART in the structures wall of the pyloric part of abomasum $(\mathrm{LSM} \pm \mathrm{SE})$ depending on carcasses conformation fatness.

\begin{tabular}{lcccc}
\hline \multirow{2}{*}{ Traits } & \multicolumn{4}{c}{ The classification according to the EUROP system / (N) } \\
\cline { 2 - 4 } & I / (4) & II / (6) & III / (5) & IV / (5) \\
\hline Subcutaneous fat (cm) & $0.5^{\mathrm{a}} \pm 0.09$ & $0.71^{\mathrm{b}} \pm 0.10$ & $0.96^{\mathrm{c}} \pm 0.14$ & $1.08^{\mathrm{c}} \pm 0.13$ \\
Marbling (pkt.) & $1.92^{\mathrm{a}} \pm 0.20$ & $2.10^{\mathrm{a}} \pm 0.19$ & $2.70^{\mathrm{b}} \pm 0.11$ & $2.96^{\mathrm{c}} \pm 0.20$ \\
Fat content (\%) & $2.47^{\mathrm{a}} \pm 0.23$ & $2.93^{\mathrm{b}} \pm 0.15$ & $2.97^{\mathrm{b}} \pm 0.25$ & $3.42^{\mathrm{c}} \pm 0.22$ \\
Perinephric fat (kg) & $1.90^{\mathrm{a}} \pm 0.21$ & $2.12^{\mathrm{b}} \pm 0.19$ & $2.42^{\mathrm{b}} \pm 0.10$ & $2.54^{\mathrm{c}} \pm 0.09$ \\
Number of CART-IR & $37.8^{\mathrm{a}} \pm 3.7$ & $31.5^{\mathrm{b}} \pm 2.3$ & $33.2^{\mathrm{b}} \pm 3.1$ & $28.9^{\mathrm{c}} \pm 2.4$ \\
Submucous plexus & $3.4^{\mathrm{a}} \pm 0.7$ & $3.9^{\mathrm{a}} \pm 1.1$ & $2.7^{\mathrm{b}} \pm 0.6$ & $2.1^{\mathrm{c}} \pm 0.4$ \\
Nerve fibres & $4.3^{\mathrm{a}} \pm 0.8$ & $4.5^{\mathrm{a}} \pm 0.7$ & $4.7^{\mathrm{a}} \pm 0.9$ & $3.6^{\mathrm{c}} \pm 0.6$ \\
Myenteric plexus & $3.5^{\mathrm{a}} \pm 0.5$ & $4.1^{\mathrm{b}} \pm 0.4$ & $4.4^{\mathrm{b}} \pm 0.6$ & $2.9^{\mathrm{c}} \pm 0.4$ \\
\hline
\end{tabular}

abc $-P \leq 0.05$, CART-IR - cocaine- and amphetamine-regulated transcript immunoreactive cells 
the amount of fat accumulated in the longissimus lumborum (LL) muscle: fat content and marbling $(P \leq 0.05)$.

Interesting results were obtained in the case of the number of structures in which immunoreactive structures of the cocaine- and amphetamine- regulated transcript (CARTIR) were identified. The wall of the pyloric part of the abomasum was found to generally contain a lower mean number of such structures in the animals whose carcasses had a higher fat content. The fat class was significantly associated with the number of CART-IR structures in the wall of the pyloric part of abomasum. The number of CART ranged from 37.8 at I to $28.9 \%$ at carcass fatness score IV. Lower immunoreactive structures CART in the cells of endocrine concentration was accompanied with higher values of indices connected with fat deposition $(P \leq 0.05)$. This relationship was confirmed in the case of marbling with the correlation coefficient of -0.514 and subcutaneous fat from -0.451 (Table 2).

Table 2. Coefficients of Pearson's correlation of the relationship between adiposity indices of bulls and the number cells of CART-IRin the structures wall of the pyloric part of abomasum.

\begin{tabular}{lcccc}
\hline \multirow{2}{*}{ Traits } & \multirow{2}{*}{ Number of CART-IR } & \multicolumn{2}{c}{ Number of CART-IR cell instructures: } \\
\cline { 3 - 5 } & & Submucous plexus & Nerve fibres & Myenteric plexus \\
\hline Subcutaneous fat (cm) & $-0.451^{*}$ & $-0.636^{*}$ & -0.288 & $-0.541^{*}$ \\
Marbling (pkt.) & $-0.514^{*}$ & -0.421 & -0.197 & -0.209 \\
Fat content (\%) & -0.304 & -0.244 & -0.355 & -0.322 \\
Perinephric fat (kg) & -0.233 & $-0.672^{*}$ & -0.223 & $-0.487^{*}$ \\
\hline
\end{tabular}

$*_{-} P \leq 0.05$, CART-IR - cocaine- and amphetamine-regulated transcript immunoreactive cells

The analysis of CART-IR in the anatomical layers of the pyloric section of the abomasum (Table 1) identified the strongest relation between the carcass fat deposition class and the number of structures containing CART-IR in the submucous plexus layer $(P \leq 0.05)$. The layer contained the lowest numbers of these structures, ranging from 2.1 (IV) to the mean 3.65 (I and II). In the case of immunoreactive structures CART in the submucous plexus, a correlation was found between the thickness of the subcutaneous fat cover $(-0.636)$ and the perinephric fat weight $(-0.672)$. The numbers of CART-IR in nerve fibres $(P \leq 0.05)$ and the myenteric plexus $(P \leq 0.05)$ were similar and ranged from 3.5 (I) to the mean 4.5 at fatness scores I, II, and III (Table 1). Data presented in Table 2 suggest that the mean number CART-IR in these anatomical layers was significantly correlated with the thickness of subcutaneous fat $(-0.636$ and -0.541$)$ and the weight of the perinephric fat $(-0.672$ and $-0.487)$

\section{Discussion}

The results of current research suggest that CART is a significant body weight and fat retention regulator not only owing to its effect on the food intake behaviour, but also due to its control of digestion and energy metabolism (Okumura et al. 2000; Aja et al. 2001; Asnicaretal. 2001; Wortley et al. 2004). However, our current knowledge and the broad spectrum of CART involvement in energetic homeostasis still preclude an explicit description of how the presence of this neuropeptide in the stomach influences the intensity of body fat deposition.

The results of the study by Qing and Chen (2007) of the amount of accumulated fat in rats show that protracted CART expression in the brain can affect the amount of fat deposited in the body. In their analysis of rats that consumed CART, the rats' body weight 
decreased, but the decrease was not correlated with the amount of deposited fat because the fat content in the test groups of rats remained at a similar level. In our study the identified correlations testify to a significant role of CART in diminishing fat retention in the bodies of the analysed bulls. However, the results of Rohner-Jeanrenaud et al. (2002) show that prolonged exposure to CART firmly antagonizes hunger and reduces the amount of absorbed food. This neuropeptide affects indirectly energy homeostasis, promotes oxidation of fats and reduces the amount of adipose tissue retention. Rohner-Jeanrenaud et al. (2002) showed that this effect remained in rats fed a high energy feed. These results show that lower food intake and body weight gain were accompanied by a reduction in plasma insulin and leptin concentrations. In their opinion, this effect is important for energy homeostasis with respect to excess body weight caused by increased appetite.

Asnicar et al. (2001) found that those animals that did not have the gene responsible for CART secretion were characterised by a far more intensive food intake. This was accompanied by an increase in the weight of body and fat tissue, as indicated also by Larsen et al. (2002) and Hunter et al. (2004).

A similar tendency in CART-IR structure concentration was observed in sheep stomachs by Arciszewski et al. (2009). The results of the above authors showed that CART coexist with neurotransmitters present in the sheep stomach. Numerous conglomerates of CARTIR nervous fibres were identified in the muscular coat of the forestomach and abomasum.

Our results show that the numbers of immunoreactive structures (CART-IR) in the anatomical layers of the abomasum wall were connected with the amount of fat deposited in the organisms of the animals. Higher numbers of CART-containing structures were generally correlated with higher values of fatty cover indices. It is important that the obtained values of the correlation between CART-IR and adiposity indices refer to the carcass fat cover indicators which influence the commercial value and cooking quality of meat. This suggests that it is possible for beef producers to take advantage of these findings.

\section{References}

Aja S, Sahandy S, Ladenheim EE, Schwartz GJ, Moran TH 2001: Intracerebroventricular CART peptide reduces food intake and alters motor behavior rat a hindbrain site. Am J Physiol 281: 1862-1867

Arciszewski MB, Barabasz S, Skobowiat C, Maksymowicz W, Majewski M 2009: Immunodetection of cocaineand amphetamine-regulated transcript in the rumen, reticulum, omasum and abomasum of the sheep. Anat Histol Embryol 38: 62-67

Asnicar MA, Smith DP, Yang DD, Heiman ML, Fox N, Chen YF, Hsiung HM 200: Absence of cocaine- and amphetamine regulated transcript results in obesity in mice fed a high caloric diet. Endocrinology 142: 43944400

Banke E, Riva M, Shcherbina L, Wierup N, Degerman E 2013: Cocaine- and amphetamine-regulated transcript is expressed in adipocytes and regulate lipid- and glucose homeostasis. Regul Pept 182: 35-40

Baranowska B, Wolińska-Witort E, Martynska L, Chmielowska M, Baranowska-Bik A 2004: Effects of cocaineamphetamine regulated transcript CART on hormone release. Regul Pept 122: 55-59

Douglass J, McKinzie AA, Couceyro P 1995: PCR differential display identifies a rat brain mRNA that is transcriptionally regulated by cocaine and amphetamine. J Neurosci 15: 2471-2481

Herman GE, Elfont EA 1991: The taming of immunohistochemistry: the new era of quality control. Biotech Histochem 66: 194-199

Hunter RG, Philpot K, Vicentic A, Dominguez G, Hubert GW, Kuhar MJ 2004: CART in feeding and obesity. Trends Endocrinol Metab 15: 454-459

IZ-INRA 2001: IZ-INRA: Standards of cattle, sheep and goat nutrition. National Research Institute of Animal Production, Krakow, Poland. Developed by INRA 1988

Janiuk I, Młynek K, Wysocki J 2013: Identification and location of the cocaine and amphetamine regulated transcript (CART) in the abomasum of cattle. Acta Histochem 115: 371-375

Kasacka I, Piotrowska Z 2012: Evaluation of density and distribution of CART-immunoreactive structures in gastrointestinal tract of hypertensive rats. Biofactors 38: 407-415

Kobayashi Y, Jimenez-Krassel F, Ireland JJ, Smith GW 2006: Evidence of a local negative role for cocaine and amphetamine regulated transcript (CART), inhibits and low molecular weight insulin like growth factor binding proteins in regulation of granulose cell estradiol production during follicular waves in cattle. Rep Biol Endocrin 4: 22 
Kong WM, Stanley S, Gardiner J, Abbott C, Murphy K, Seth A 2003: A role for arcuate cocaine and amphetamine regulated transcript in hyperphagia, thermogenesis, and cold adaptation. FASEB J 17: 1688-1690

Koylu EO, Couceyro PR, Lambert PD, Ling NC, DeSouza EB, Kuhar MJ 1997: Immunohistochemical localization of novel CART peptides in rat hypothalamus, pituitary and adrenal gland. J Neuroendocrinol 9: 823-833

Larsen PJ, Vrang N, Petersen PC, Kristensen P 2000: Chronic intracerebroventricular administration of recombinant CART (42-89) peptide inhibits and causes weight loss in lean and obese Zucker (fa/fa) rats. Obes Res 8: 590-596

Larsen PJ, Vrang N, Tang-Christensen M, Jensen PB, Hay-Schmidt A, Romer J 2002: Ups and downs for neuropeptides in body weight homeostasis: pharmacological potential of cocaine amphetamine regulated transcript and pre-proglucagon-derived peptides. Eur J Pharmacol 440: 159-172

Lucidi P, Murdolo G, Di Loreto C, Parlanti N, De Cicco A, Fatone C 2005: Metabolic and endocrine effects of physiological increments in plasma ghrelin concentrations. Nutr Metab Cardiovasc Dis 15: 410-407

Méndez-Díaz M, Domínguez Martín E, Pérez Morales M, Ruiz-Contreras AE, Navarro L, Prospéro-García O 2009: The anorexigenic peptide cocaine-and-amphetamine-regulated transcript modulates rem-sleep in rats. Neuropeptides 43: 499-505

Młynek K, Janiuk I 2013: Detection of cocaine and amphetamine regulated transcript in the abomasum of slaughtered bulls with different daily body weight gains. Acta Vet Brno 82: 253-257

Okumura T, Yamada H, Motomura W, Kohgo Y 2000: Cocaine amphetamine regulated transcript (CART) acts in the central nervous system to inhibit gastric acid secretion via brain corticotropin- releasing factor system. Endocrinology 141: 2854-2860

Qing K, Chen Y 2007: Central CART gene delivery by recombinant AAV vector attenuates body weight gain in diet-induced-obese rats. Regul Pept 140: 21-26

Rohner-Jeanrenaud F, Craft LS, Bridwell J, Suter TM, Tinsley FC, Smiley DL, Burkhart DR, Statnick MA, Heiman ML, Ravussin E 2002: Chronic central infusion of cocaine- and amphetamine-regulated transcript (CART 55-102): effects on body weight homeostasis in lean and high-fat-fed obese rats. Int. J Obes Relat Metab Disord 26:143-149

Smith GW, Sen A, Folger JK, Ireland JJ 2010: Putative role of cocaine- and amphetamine-regulated transcript (CART-PT) in dominant follicle selection in cattle. Soc Reprod Fertil Suppl 67: 105-117

Schwartz MW, Woods SC, Seeley RJ, Barsh GS, Baskin DG, Leibel RL 2003: Is the energy homeostasis system inherently biased toward weight gain? Diabetes 52: 232-238

Thim L, Kristensen P, Nielsen PF, Wulff BS, Clausen JT 1999: Tissue-specific processing of cocaine- and amphetamine-regulated transcript peptides in the rat. Proc Natl Acad Sci 96: 2722-2727

Valassi E, Scacchi M, Cavagnini F 2008: Neuroendocrine control of food intake. Nutr Metab Cardiovasc Dis 18: $158-168$

Vettor R, Fabris R, Pagano C, Federspil G 2002: Neuroendocrine regulation of eating behavior. J Endocrinol Invest 25: 836-854

Vrang N 2006: Anatomy of hypothalamic CART neurons. Peptides 27: 1970-1980

Wierup N, Gunnarsdo A, Ekblad E, Sundler F 2007: Characterisation of CART-containing neurons and cells in the porcine pancreas, gastro-intestinal tract, adrenal and thyroid glands. BMC Neurosci 8: 51

Wierup N, Kuhar MJ, Nilsson BO, Mulder H, Ekblad E, Sundler F 2004: Cocaine- and amphetamine regulated transcript (CART) is expressed in several islet cell types during rat development. J Histochem Cytochem 52: 169-177

Wierup N, Richards WG, Bannon AW, Kuhar MJ, Ahren B, Sundler F 2005: CART knockout mice have impaired insulin secretion and glucose intolerance, altered betacell morphology and increased body weight. Regul Pept 129: $203-211$

Wortley KE, Chang GQ, Davydova Z, Fried SK, Leibowitz SF 2004: Cocaine- and amphetamine-regulated transcript in the arcuate nucleus stimulates lipid metabolism to control body fat accrual on a high-fat diet. Regul Pept 117: 89-99

Yang SC, Shie KR, Li HY 2005: Cocaine and amphetamine-regulated transcript in the nucleus accumbens participates in the regulation of feeding behavior in rats. Neuroscience 133: 841-851

Zhang CL, Chen H, Wang YH, Lan XY, Lei CZ, Fang XT 2008: The polymorphisms of bovine cocaine- and amphetamine-regulated transcripts and their associations with cattle (Bos taurus) growth traits. J Biosci 33: $365-370$ 